\title{
Spatial Paradigms in the Travel Park: Sowing the Programmatic Field
}

\author{
NINA HOFER \\ University of Florida \\ USA
}

\begin{abstract}
This paper attempts to provide a model for meaning by reading the overlay as potential in a banal - if not bizarre contemporary project: a Chinese theme park in Orlando Florida. Proposed to prospective visitors as "Authentic" it is in fact an extraordinary collision of temporally and culturally distant spatial concepts and building practices. This paper uses an experimental 'witnessing' of the park to lay out a series of spacio-conceptual models for travel as power. These range from looking at the theme park as a Chinese propaganda tool, through Bachelard's concepts of miniaturization and collection, empirical (Chinese) versus theoretical (American) standards for life safety, spatial strategies of 11 th century Dream Journey Scrolls, and Feng Shui (the art of Placement) The changing nature of architectural practice instigates a movement from building representations of singular architectural ideas to the constructions of more complex 'programmatic fields.' We need neither despise nor formally caricature the polyglot programmatic shifts and collisions of our time. This paper takes a hopeful stance, maintaining that the overlay of resonant paradigms provides an opportunity not realized, perhaps, in the existing construction.
\end{abstract}

\section{SPATIAL PARADIGMS IN THE TRAVEL PARK: SOWING THE PROGRAMMATIC FIELD}

Splendid China is a Chinese-themed attraction that takes visitors on a 10,000 mile journey through 5,000 years of Chinese history and culture on a stunning 76acre park-like setting. Visitors can explore more than 60 incredibly detailed miniaturized replicas of China's most historic landmarks, including a half-mile long Great Wall, the Forbidden City, Tibet's Potala Palace, the Terra Cotta Warriors, The Stone Forest of Yunan, life-size Suzhou Gardens and more. Live Chinese entertainment includes dancers, acrobats, martial arts demonstrations and jugglers. Also shopping for Chinese merchandise, souvenirs and authentic Chinese cuisine, including tasty Chinese take-out! $A$ visit takes a half-day or more. Located 12 miles southwest of Orlando on Highway 192 in Kissimmee, FL, only one mile west of Walt Disney World's main entrance road. Discount for groups. Open daily. “ - Splendid China Press Release

"It's a splendid idea, but not for the reasons they think..."

- Lily Chi, Conversation

\section{THE AP NEWS PHOTO: \\ A FICTION OF POLITICAL ACQUISITION}

The AP image of weeping Buddhist monks at the protest at the opening of Splendid China's Theme Park generated an 'impression count' of 16 million. This fact far outweighed any concern about the negative publicity that it might generate. And in fact, the news (like the constructs in the park itself) was staged for the camera. Organized by the International Campaign for Tibet, the protest marshaled all of eight people for the opening festivities. It seems that the Tibetan group did not want their "Ayre's Rock," their most holy site, to be claimed as one of China's 60 greatest scenic possessions. They point out that the "Chinese propaganda theme park whitewashes Chinese treatment of Tibetans, Mongolians and other minorities under the rule of the Peoples Republic, creating a fiction of a diverse and peaceful Chinese nation." And so it does, including, in the garden of realistic miniatures, tiny ceramic figurines of happy Dai, Mongolian and Tibetan peoples in undisturbed "ethnic villages." But the real-time fiction of the park is more disturbing than these minute illusions of serene coexistence. Over one hundred highly skilled craftsmen came to the US for a period of two years to build the full-scale portions of this park. They were housed in a large pink barracks, outfitted with ping-pong tables and VCRs. They rarely left; they didn't even go down the road to Disney. One could imagine what any realization of the market value in Florida of their extraordinary craftsmanship might have done to the deadlines and budgets of the park. The performers who entertain visitors are also primarily ethnic minorities whose homes are nostalgically invoked in the miniatures around which they juggle and dance. When 
interviewed in Chinese and out of earshot of their employers, they say that their activities and ability to circulate freely are regulated for fear that they will defect. "Our situation," they murmur, "is somewhat difficult."

Then there are also sins of omission. The park's stated intention is to educate Americans about China and to encourage tourism. Its public relations squibs suggest that the park provides a visible symbol of a resurgent China in which past and present are interwoven - but exhibits, promotional literature, shops and miniatures aggressively erase the Cultural Revolution. All I wanted to buy was a miniature Mao jacket; they sell embroidered Mandarin silk. The public views the Imperial Palace, The fact that the viewpoint has you standing on what is now Tianamen square is never mentioned. The biggest problem facing the public relations team, I was told, is overcoming a "30-year information blackout regarding China." Their antidote seems to be a blackout of the last 30 years of Chinese history. Is this official dis-informationor simply the visual equivalent of "easy listening?" Public relations has repeatedly disavowed financial or political involvement with the Peoples Republic of China. But other sources suggest that the majority of China Travel Services is "owned by the Mainland Chinese government" and used as the "government arm for tourism," with Splendid China enjoying the "participation and endorsement of the hard-line leadership in Beijing." The wall Street Journal is researching a story that suggests that the entire venture is simply a means of funneling money out of Hong Kong before 1997. The public relations department will concede that "Splendid China has a line of credit with a Chinese bank-whether they use it or not is up to them."

This fictional world is constructed by repressing a story of cultural negotiation and conflict. In imagining a minor intervention which might reveal this I am reminded of the man who hung his artwork quietly in the Museum of Modern Art, where it hung for a day before anyone noticed. Someone should install and photograph a guerrilla installation of thousands of tiny ceramic figurines of tanks and student protesters. Or weeping Buddhist monks.

\section{THE VIDEO: A FICTION OF FABRICATION}

The craftsmen formed a team culled from all over China; the last project that this group worked on was the Suzhou Pavilion in the Metropolitan Museum of Art. The Met sells a video of them working on the permanent installation-in silence, in half-darkness, in isolation. The work in Orlando had little in common with this reverential artistic process. The press briefings insist upon the absolute authenticity of the construction process. But there is another story of undisclosed conflict, another fictional world to be told here.

Splendid China displays an architectural story of cultural negotiation and confrontation: Architectural Practice Here and Now, Orlando 1993. It began as a business partnership between Taiwanese refugees and a Hong Kong businessman. Seventy-five acres of wetland in Orlando were held by the
Chen family and American Eastern International Corporation of Los Angeles. Mr. and Mrs. Chen escaped Communist rule 44 years ago. Their son George grew up in the USA. The development money was put up by Ma Chi Man of China Travel Services (in alleged partnership with the Peoples Republic of China). The local architect hired to oversee the construction of the park was CT Hsu, also Taiwanese. A number of details reveal the overlays of this polyglot process. If a video of this process of fabrication were to be made, it would look more like MTV, with the following scenes included:

Scene 1: The working models at CT Hsu which attempted to model the sinuous curves of the serpentine plaster walls (with their impossibly delicate latticework inlay screens) in foam core. Lily Chi tells me that these exterior walls in China traditionally served the purpose of transforming what is of necessity a boundary into a continuous undulating surface which by virtue of its topological qualities simultaneously suggests solidity and infinite atmospheric depth. What a concept for the edge of a theme park! But the materials of fast and dirty modeling in the West are so unremittingly Cartesian

Scene 2: The Book of Joints. Apparently, standard practice in China holds the architect responsible for interval, placement and proportion, while the craftsmen/carpenters/ builders are responsible for the details. The wood building systems replicated here have a consistent structural and modular system; what differs by region and type are the nature of the joints and the filigree work at the edges. When it came time to assess the structural stability of these constructions, the engineers wanted information regarding the connections. This was hard to come by. The architects didn't know; the craftsmen could build, but couldn't draw or model them. There were, however, a set of books-a morphology of joints-which the carpenters used. Simple three-dimensional drawings referred to (rather than fully explicated) the complex knots where these members meet. They probably had great names.

Scene 3: The flimsy metal ribbon straps which are appended at every major joint Chinese working drawings were submitted as schematic representations of style and proportion. These were scanned into the computer and translatedfrom metric to English measure, from Chinese to English language, from proportion to number, from parameter to specification, from image to code. The Chinese were asked for calculations of the structural capabilities of their building systems. The proofs they submitted were empirical, which is consistent with the historical basis of their sciences. But arguments of longevity were insufficient basis for engineers of record to sign off on buildings of public assembly in Orlando; and the Chinese refused to change dimensions or upsize beams on the ground that any proportional change "destroyed" the architecture. So every "authentically detailed Chinese masterpiece" contains a second full set of structural details. Each renders the other suspect.

Scene 4: For the Met installation, workers in China logged the Nan wood from remote valleys in Sichuan 
province, a fine timber site favored by the imperials in the Qing period and unused since 1949. The Suzhou Lumu Imperial kiln of 1796 was reopened for the firing of the tiles. A fourth scene from the Splendid China video would show the great pink barracks which housed the craftsmen-workers for two years. It contained their living quarters and the many thousands of telephone poles from which the full scale buildings at Splendid China were made. In an authentic simulation of ancient Chinese building practices, they whittled pressure-treated telephone poles, played ping-pong and watched Terminator II.

Scene 5: Underlying all the rest would be repeated flashbacks to the worker whose sole function, apparently, was to chisel concrete to look like granite paving stones. I am told that he did this for a year, quietly chiseling his way past drainage details reminiscent of highway construction. He stopped abruptly in front of the Imperial Palace, leaving a ragged edge of chisel tracks infiltrating Tianamen square. Was it time to go home - or did he finally lose faith in the illusion of a Splendid China?

\section{THE LOGO(S): A FICTION OF NAMING}

The first thing that struck me about the park was its signage problem. Theirs is not exactly a catchy logo-for Orlando, the City of Billboards. In fact, the official logo appears to be an airlines insignia. Posters, tickets, T-shirts and napkins are adorned interchangeably with Chinese characters, ornate dragons, Buddhas, ethnically costumed Chinese faces, pandas, tigers, or $\mathrm{Na} \mathrm{Na}$, the seven-year-old "wonder-gymnast." The image of a seamless, unified China gives way to a scattershot of tourist bait, revealing the volatile evolution of the park's typological definition. It is not a theme park, public relations stated at the outset: it is "an outdoor art park." Later it becomes a "cultural theme park," a "history theme park," an "outdoor museum." Later still, "a priceless ( \$100 million) representation of culture" and "a microcosm of China."

I am told repeatedly that Splendid China was never intended as a money-making venture. But down the road from Disney and around the corner from Sea World, the desire to compete seems irresistible. The newly minted NaNa sounds a lot like Shamu and looks a lot like Mickey. Promotional material masterfully splices the allure of their famous neighbors with not-so subtle put-downs: "An entire nation has grown up alongside the fantasy castles, diving whales and motion picture street sets that have made the Orlando area famous. In an area known as much for fantasy as any camera toting visitor can digest in a week, splendid China is boasting that it features something really different: reality." The park aims to attract only one tenth of the 12 million people Disney attracts each year. The strategy seems to be to use Disney to lure visitors to Orlando, and then make them feel guilty. Splendid China offers a moral alternative to the surfeit of pleasure which gluts the average tourist here. The target audience is National Geographic readers. On a non-game day of World Cup Week last year the place was virtually deserted.

There is no equivalent for "public relations" in Chinese. Early on in the process, China Travel Services hired theme park consultants, but rejected their signage schemes and refused to change anything from the prototype in Senjhen. Two years later they have an in-house public relations department staffed by 1 man who worked for Disney in the 70s. I am told that the park's problem in attracting visitors is education (or a lack thereof) the average American, apparently, "thinks China is blue and white and sits on the table." And while Disney proposed its own history theme park in Virginia, Splendid China's playgrounds for children, live performances and nighttime light-and-sound shows make it look more and more like a conventional theme park. The problem, I am told, is that it is "just past the entry to Disney"-as if State Route 4 were a one-way street. I predict rides and the emergence of $\mathrm{NaNa}$ as spokesperson within another two years.

\section{THE POSTCARD COLLECTION: A FICTION OF ORDER}

To get any further, one must choose to believe that the park was never a money-making venture, nor a propaganda tool for the Peoples Republic of China. The Chinese insist that Splendid China can provide an experience otherwise unattainable to the average American-namely, visiting China. I decided to eschew an initial cynical attribution of seductive intent (supported by the presence of a China Travel Services agency office one must pass when leaving the park) and take seriously for a moment the idea of this being a substitute for a journey in China. I took on the hypothetical persona of the ideal visitor to the park. This was easy: I am in fact an avid traveler, a National Geographic subscriber, and my two year old son does not allow for serious travel.

But If I were to travel to China, I would plan my trip around some organizing theme. And I would come back with souvenirs—objects and pictures to relive my trip. Crafts are provided in the Suzhou Street marketplace; but, oddly enough, no picture postcard set. The 60 important Chinese monuments as they are presented: a mini-encyclopedia of sorts. Bachelard wrote in his essay "on Miniature" in the Poetics of Space: "Miniaturization is coincident with possession... Value is enriched and condensed in miniature... In distant miniature disparate things become reconciled. They can offer themselves for our possession while denying the distance that created them. We possess, peacefully from afar the impression of domination." If miniaturization is not simply a sign of their desire for possession, perhaps it is intended to stimulate and (partially) satisfy mine; a trip around this park is meant to allow me to acquire the images of these desirable objects and thereby possess China. If it were a Western architectural history park, a set of informative postcards would be available for purchase. The challenge here, I surmised, could be that of a treasure hunt the 
visitor must acquire the information, to get the right shots, to understand their categories and order. I imagined that my photographs would form a collection, a souvenir of my visit, a set with some underlying consistency, with subsets differentiated by region or type.

As I walked around the park attempting to execute this intention I began to feel uneasy. I hate to call Splendid China "inscrutable," but it certainly resists being scrutinized at every turn. Labels, only recently posted, name rather than explain. Even more disconcerting, there is no discernible ordering scheme to the placement of miniatures. My encyclopedia had entries but no information. This history theme park was not working on any linear chronological representation of history. Nor was there any apparent mapping of China's geography onto the 75 acres of the site. There can be no collection without categories. The National Geographic model of intellectual and visual possession was clearly not providing a resonant model for the park. I began to look for a new approach.

\section{FENG SHUI SHIELDS AND MAGNETS: A FICTION OF PLACEMENT}

Authenticity is a big word at Splendid China. And certainly for the National Geographic reader/avid traveler, the goal is to find the "real China." The use of number attracted my passion as a collector, but there was no apparent order, at least in the traditional Western sense of the word. "Collecting all 60!" would in no way create a telescoping cycle of completion, such as that which is laid out by my fresco set of the Arena Chapel cycle. The park's second most frequent claim is that its exhibits exemplify Chinese culture. I began to think about Chinese forms of order.

From tourist in search of souvenirs to selectively informed traveler, I proceeded to look for the one thing I knew about the Chinese culture: historically it has deployed 'ordering' strategies which proceed from synchronicity (the local and the coincident) rather than from statistics (the generalization or the rule). There exists a science/philosophy/art called Feng Shui (translated as Wind and Water), usually referred to in the literature here as "the Chinese art of placement." This extraordinarily complex topic seems to rest on an understanding of the architectural construction as an intervention which emerges from within and adjusts a field of spatial-temporal forces which preexist its construction. Its concern is not with the solid object in an infinitely divisible space, but with a dense and fluid space which is continuous and extensive.

The most apparent contemporary manifestation of this mindset is a thriving profession of Feng Shui masters who assess the chi value of any scale of construction and suggest interventions which will channel the forces in a more benevolent way. Their suggestions are minor and practically facile; paint a wall orange, add a mirror, a fish tank, a plant, re-orient your bed, plant a glade of bamboo. But most of the constructions represented in this park are sure to have been considered originally as Feng Shui shields and magnets-at a scale which ensured luck to a region, if not the nation. They might have been placed in the valley of balance between the tiger and the dragon mountains, or deflected the chi arrows of a river. The Great Wall was considered a Feng Shui nightmare as it 'cut the veins of the dragon.'

I attempted to understand each installation as a knot in the configuration of its immediate topographical placement. This didn't work either. The super-imbued landscapes from which these constructions emerged are neither lovingly replicated nor authentically detailed. While the monuments are set within an undulating field, it is a topography which exists at the scale of passage for the visitor, rather than siting for the buildings. Any indeterminacy of figure-ground is lost completely as the buildings are objectified in their miniaturization. The Chinese architects never mentioned Feng Shui to Nancy Prine, the landscape architect for Splendid China. When I asked Susan Hong-lin, a Chinese architect in the public relations department, whether Feng Shui had played any part in the conception or construction of the park (after all, I.M.. Pei has used Feng Shui masters for some of his buildings), I was told that although some-mostly people from Hong Kong - believed in these superstitions, she was an architect and was more rational. I began to feel hopelessly academic.

But the reference is provocative. The science of Feng Shui fundamentally challenges the idea of the architectural object as figure, its relationship to the ground on which it sits, and of the authority of its maker. It is strikingly relevant to contemporary architectural discourse. The image which has always come to my mind when reading about it is that in it, architectural making approximates putting your finger into flowing water. The flow-structure that forms is catastrophic in the terms of Rene Thom, both stable and chaotic, a dynamic equilibrium, achieving form somewhere between my actions and those of the space within which I act. What happens when these live organ-things are removed from their body-sites? If the site retains the architecture, they have as little relevance as a jelly-fish in a parking lot or a placenta in a bucket of formalin. If, however, they retain it they are the chi equivalent of radioactive. Suddenly, taking them out of their force-fields and putting them all together in one park becomes a little frightening — one walks between them either in a neutral morgue space or in a hyper-charged space of loose archivectors. How do I photograph ripples without water? While the possibilities are enticing, this "way" was not going to shed light on the park as built. These buildings are clearly not intending to reference their original social, political or philosophical intentions. I mentally put the wideangle lens away.

\section{THE MACRO-LENS: A FICTION OF INHABITATION}

Back to "authenticity." Here, the big deal is "authentic" fabrication: these are "perfectly detailed" miniatures, con- 
structed "exactly like the originals." In other words, no matter how close you get to them the illusion will hold up. Brick for brick, potentially they create pictures for the tourist that could have been made at the original site. Six million tiny bricks in the Great Wall alone! My attempts to get some distance-to take meaningfully sited shots of them-were foiled. Perhaps, I thought, these constructions aspire to the condition of the bonsai trees surrounding them - the closer you get, the more complete the illusion. I began to think more closely about Bachelard's essay on the miniature.

He begins by stating the "psychological importance" of scale. Where "a geometrician sees exactly the same thing in two similar figures drawn to different scales, "he says, the phenomenologist understands that the miniature is "an inversion of observation... the mind that imagines follows the opposite path of the mind that observes.... Miniature causes men to dream." And this dream is to be one of mental occupation. It is about relative size; ours and the object proffered to the gaze. "As one enters into a miniature world, images abound, grow and escape... large issues from small thanks to a liberation from all obligations of dimensions, a special characteristic of the activity of the imagination." $\mathrm{Mr}$. Ma claims that he first conceived of Splendid China when he visited Lilliput in Holland. If we look at the European miniature park as the ostensible prototype, we find the miniatures there set into a landscape of perspectival aids. For those of us with inelastic spatial imaginations, these will overcome physical limitations to provide the illusion of occupying the constructs. But none of that occurs here.

There is a crucial distinction between Bachelard's miniatures and those at Splendid China. It is impossible to get an inhabitant's view of these constructs. the previous shot is a pr shot; A distance of ten or 20 feet from the models is rigidly enforced-far enough that the craftsmanship could just as well have been simulated. We cannot get near them. The view that is given is definitely bird's eye. Photographs of the park always include a gargantuan visitor in the fore- or midground. Bachelard's miniatures are an invitation to proximity, to the intimacies of penetration. This miniature park simulates and promotes distance.

\section{THE 'BIRD'S EYE' VIEW: A FICTION OF ILLUSION}

There was still an image to be made. I bought one of the panoramic cameras which are sold at every intersection in the park, and began to take bird's eye perspectives of each display. The tiny pavilions with their bonsai plantings sat uneasily within the vertical format, creating strange planar overlaps with full scale visitors, trees, park benches and concession stands. The images in my view finder immediately called to mind Chinese hanging scrolls, with the multiscalar landscapes replaced by the appurtenances of the theme park. I began to look into scroll painting in hopes of finding a source for a Chinese phenomenology of the miniature.

The most cursory research turned up a host of resonant attributes. Chinese landscape and garden design is inextricable from the Art of Landscape Painting. The golden years of landscape painting occurred in the 12th c. Sung Dynasty, and focused on the idea of simulated travel. The descriptions of these works, in even the most general survey works, could describe Splendid China: "characterized by the encyclopedic juxtaposition of elements from different parts of China, multiple scales and the shifting viewpoint," "Geographical and historical connections are erased and so is connection to a complete scene," "Insistence on the importance of physical substance," "Attention to things and the accurate description of them," "Details so fine that even under magnification they retain their integrity of their physical likeness." The "objectevents" in these paintings, which frequently revolved around a referential architectural construction, were always rendered in bird's eye perspective - even when more than one occurred in a landscape which was in other ways preoccupied with the illusionary devices of distance.

\section{THE 'PRIVILEGED' VIEW: A FICTION OF REALISM}

When $\mathrm{Li}$ Cheng painted such buildings as pavilions or towers on a mountain, he always did the flying eaves as if one were looking up at them. The explanation is given that one is viewing what is above from below, just like a man on level ground looking up at house eaves sees their supporting rafters. This theory is wrong... Master Li evidently did not understand the method of taking the larger view of the small.

$$
\text { - Shen Gua }
$$

cited in Valerie Ortiz, "A Twelfth Century Chinese Pictorial Dream Journey." The Art Bulletin, June 1994, pp. 257 - 278.

Shen Gua's dismissal of the ephemeral occupational viewpoint is not a dismissal of realism. It depends on the idea that each object has a privileged view which is "essential," without necessarily implying reduction or abstraction. Tremendous emphasis was placed on observation - on the creation of exact replica through mimesis of the world. The "privileged view" provided a commonly held framework within which to observe. These privileged views were iterated in exotically structured encyclopedic morphologies. For example, in 1121 Han Cho writes a treatise on landscape painting which designates 40 types of mountains, including those that are "excessively tall," "blue-green," "hall-shaped," "shaped like a screen" and "long and having a ridge." Similar morphologies are mapped out for valleys, water, forests, trees, clouds, mists, misty luminosities, wind, rain, snow, fog, figures, bridges, gateways, walls, temples, monasteries, mountain retreats, boats, the four seasons and distance. These encyclopedias are suggestive rather than explanatory, imaginative rather than rational, proximal rather than classificatory, elliptical rather than straightforward, and openended rather than striving for closure. "Realism" in the 
details was a judicious blend of the most minute observation and the correct (resonant) identification of the morphological type. By this definition, it shouldn't matter that the architectural sites for Splendid China were removed from their original surroundings. The combinative strategies in landscape painting create visionary projections rather than remembered landscapes. "Realism" in the assemblage depends on the invention of a morphologically significant context of landforms.

In vertical landscape scrolls we are simultaneously within and outside of the painting. One set of visual cues consists of vanishing points at our eye level and tiny figures that invite us to project ourselves into an intimate mental association with the travelers depicted within the scroll. These connect the space of the viewer to the space of object-event, creating a perspectival reading. The second set links the space of the pavilion to the far distance, giving us a tipped plan view, a remote view contrary to experiential perspectival orders. In this view the depicted traveler is specifically not us. Valerie Ortiz calls the first set "empirical" and the second "theoretical," and suggests that the spatial conflict created frees us from the constraints of rational order and sets us free to dream. Michel de Certeau calls the first idea "itinerarial"and the second "panoptical." He states that the juxtaposition within a single text allows for the creation of "spatial stories." Both would agree that the device shifts attention away from the representation of the painter's view and creates a textual condition which activates the viewer. The reality depicted here is the reality of the perception of the painting, which Lily Chi calls "eye-time."

\section{THE PLAN: A FICTION OF DISTANCE}

Kuo Hsi says, "There are three [modes of rendering] distance in [painting] mountains. Looking up at mountains from below and seeing pale mountains in the background is called 'high distance;' looking from in front of mountains and glimpsing the mountains behind is called 'deep distance;' looking from a near mountain to a neighboring low-lying mountain is called 'level distance.' I would like to suggest another three distances When from the near bank of a broad body of water one can see mountains far, far off, it is called a 'broad distance'; when mists and clouds cloak and obscure, and, cut off by a wilderness stream, one can see almost nothing beyond it, this is called 'shrouded distance'; when the objects in a scene are extremely fragmentary and everything is indistinct and mysterious this is called 'illusory distance...

- Han Cho in Shan-shui ch'un-ch'an chi

(A.D......1121)

cited in Valerie Ortiz, pp. $257-278$.

Kuo Hsi's definitions of distance require two sets of information; where we are standing and where we are looking. A morphological signifier for distance cannot be determined without understanding the relative position of the viewer,
Han ho adds a third variable; how the visual information is received and internalized. Chinese landscape is obsessed with the illusion of distance; but this does not lead at any point to the implementation of a diagrammatic perspectival system. This is in no way a failure of description; their parameters for the experience of distance make ours look formulaic.

I looked in vain for the application of this sensibility at Splendid China. The topography is certainly convoluted. and Morphological essence-landscapes like the Stone Forests of Yunan are represented in the park in miniature. But the landforms which contain the exhibits themselves are all at the same scale, which exactly mediates between visitor and exhibit. Furthermore they are as neutral in form as they could possibly be while still creating an undulating surface on which to scatter the miniatures. It is always the exhibits which are on a hill; the path we take is devoid of incident. The plantings form a perfect visual inversion inspired by a desire for scalar continuity, with miniatures giving way gradually to medium scale plantings and then to trees which, in time, will shade the visitor's path. Although the premises of "reality" are constantly redefined as one looks back and forth between the detail and the point of view, the 'illusion of distance' and a user-friendly path bear little relationship to the complexities of 'eye time' as described by my sources on this tradition.

The landscape architect at Splendid China told me exactly two things. The first explained the problem; she immediately stated that the landscape at Splendid China was built around vistas, creating the illusion of distance by playing the near exhibit as a focal point against others which function as backdrop; a complete reversion to western parameters of distance thinking as filtered through theme park oversimplifications of theatricality. The second was an interesting footnote in the ongoing story of translation and countertranslation which characterizes this park; The Chinese landscape architect selectively didn't follow her plans, and what he took out were the 'transitional plantings.' They have since been re-inserted; but could this apparently chronic insubordination be a faint echo of the juxtaposition of scales in a state of rupture so effectively manipulated in the 12th century scrolls? The landscape painters of the Sung opened up the concept of the vista to the expanded spatiality of multiple scale and position. The results differ significantly from collage space, since the object is never fragmented, maintaining an unbroken relationship between the part and the whole. This type of juxtaposition exerts tremendous demands on the spatial matrix.

\section{"EYE-TIME:" A FICTION OF ITINERARY}

The challenge which defined the horizontal travel scroll was the articulation of the spatial matrix, opening up the concept of the panorama to time by composing a non-sequential and non-simultaneous set of independent local views in a single scroll. Valerie Ortiz writes in the June 1994 Art Bulletin 
about a 12 th century scroll entitled "Dream Journey on the Xiao and the Xiang." This uncannily pertinent article describes a seminal work of landscape painting which "depicts a real place desired by all travelers"-and just happens to be the region of China in which the original Splendid China is located.

The Dream Journey visits a set of eight object-events, referring to specific destinations in the area between the Xiao and the Xiang Rivers. These object-events and their land-morphs formed signs which were understood explicitly as constituting a multi-tiered combinative language. The set was determined by convention; artistry was displayed in the sequence of their combination and the choice and execution of spatial strategies which bridged between the elements. "Each segment focuses on an independent view seen at a particular time and from a particular vantage point... perception fluctuates between the space that is represented and framed and the space that structures such presentation" (Ortiz) This structure explicitly paralleled contemporary poetry in two respects: it set its image content into a linguistically significant spatial structure; and it avoided narrative sequence, thereby insisting on individual acts of interpretation and an active reader. Space and time are transformed: as for Aristotle's kinetic school, movement and space are not separate from thinking and perceiving.

The horizontal handscroll type carries a striking resonance with the paradigm of the travel park - the site plan for Splendid China is now readable to us as an unsophisticated travel itinerary in the tradition of the Dream Journey Scrolls. Two distinct scales are immediately apparent in the landscape plan. Any element belongs either to the world of the miniature (space that is represented and framed) or the world of the visitor (space that structures such presentation). The framed views, or vistas, are set in an indeterminate field of nodes which allow visitors to chart their own narrative sequences. But unfortunately, the spatial matrix is vague. The effect in Splendid China is most similar to the earliest Chinese landscape painting, which uses "space cells" to organize a series of object events - staggered islands in a sea of flat indefinite space. At its best, this space has been described as "silk space" in a manner which most closely approximates contemporary musings on the nature of the Platonic chora-a cosmogenic, womb-like void.

As the art form evolved, this space became increasingly articulate. Ms. Ortiz' observations on the spatial structures which create 'poetic space' in the Dream Journey provide a tactical manual for the grafts and ruptures which should sew together the multiple scales, locations and constructs of Splendid China. Terms such as "oblique counter-thrusts," "counter positioning of focal points," "juxtaposition of distance and proximity," "movement in slices," "shifting perspective, ambiguous recession, weightlessness," "layering of stage flats," and "coincidence, overlap, interpenetration and blending" lay out a formal vocabulary which begs for an architectural analog here.
The park as built is an unhappy compromise in which the expanded view from the individual event is neither provocative nor reassuringly familiar. During the day, visitor and exhibit scales create an uneasy state of hierarchy without degree or mediation; the effect is more successful at night. Many of the transitional devices used by the Southern Sung painters depended on ink wash techniques which offered a catalogue of ways to graft obscure spatial joints. The smoothness of these shifts determined the ability of the scroll to create an aura of dream and recollection.

\section{THE PROGRAMME: A FICTION OF ALLUSION}

The core of the dilemma for Splendid China can be summarized in the confusion surrounding the name of the area through which one enters the park: Is it Suzhou Street or Suzhou Gardens?

The original map of the full scale complex is labeled "Suzhou Gardens," a term which refers to a particular 17th century garden type which created a three dimensional/real time/physical analog to the "poetic space" of the dream journeys of 12 th century Sung travel scrolls. As early as the fourth century, Chinese royal parks were landscaped to replicate particular travel sights: the Eastern Sea, the Blessed Isle, Mount Kun'lin. By 700 A.D., the miniaturization involved in such replication had developed into an elaborate art form called "tray scenery," familiar to us in its development as bonsai . Landscape painting and the garden developed together around this idea of the journey, evidence of travel's incalculable importance to the educated man. This travel had little to do with American tourism with its connotations of vacation, pleasure, "taking a break." Rather, it was defined here as work. The educated man must "read ten thousand books and travel ten thousand miles" (T'ung Ch'i Ch'ang, cited in Ortiz). The sequential visit to important sites had as its goal the accumulation of experiences rather than of facts and images.

No one affiliated with the park has even heard of this precedent. The term Suzhou Street has no Chinese point of reference; the phrase apparently emerged because the architecture attempts to simulate that of a traditional artisan's street in the 13th century city of Suzhou, a cultural and artistic high point in the history of China. However, the term itself-used by the public relations department and the Orlando construction team-seems to refer most directly to "Main Street USA," through which one enters Disney World. This alternation of terms directly manifests a continuing tension between an ascendant Western desire for marketing and possession and a barely surviving cultural imperative to initiate a dream journey.

Lest you suspect that all of this is irrelevant rather than supplementary, let me just add that Last year China Travel Services privately published a children's book entitled $A d$ venture in Splendid China. In it, a culturally diverse group of five children are taken to Senjhen by their business traveler parents. They meet a mischievous character named 
the Monkey King. He takes them on a dream-like fantastic journey through Splendid China. While lying down, of course.

\section{THE PROJECT: A FICTIONAL ASSIGNMENT}

The most distressing impression you could have received from my talk would be that some quintessential Chinese art work has been corrupted by its implantation in our consumer culture. This conference is predicated on the understanding that it is far more complicated than that. The initial proposal for the park in Senjhen is more Disney than travel scroll. But the mixture there is highly successful; that park is thriving. My search for resonance (rather than meaning) in the park's spatial structure comes from my basic orientation as a designer and educator, a conviction that the program ultimately yields architecture. I am bored by the argument that the theme park is both emblematic of our culture and proposes either no possibility for a public realm, or a completely individual and consumptive model. Clearly Splendid China has many such models. Could their struggle to "find a way to overcome the limitations of the American attention span" allow the park to retain and augment its reference to the dream journeys of the Southern Sung? This begins to seem like an ideal hypothetical design project: a nomadic construction which refers simultaneously to the practices of a remote exotic art form with highly developed spatial and compositional strategies, and an absolutely familiar contemporary cultural banality - the tourist and the theme park.

\section{Program as generator in a geography of power}

For the National Geographic set, this has replaced that. 'Armchair travel' has replaced the garden and the 'dream of travel.' How can we reinvest the architectural construction on the site of Splendid China?

You will need to look through apparent similarities to Disney World and Universal Studios to realize the models, still imbedded, from which this idea-which is essentially foreign to our spatial practices - emerged. Then you will need to adopt some other Western paradigm which can provide a familiar analog to incite the interest of the American tourist.

Splendid China needs to be both "world making" and "world recovery" - both Bachelard's dream and the dream of travel.
Your architectural proposals may take one of several forms:

- Assignment 1. The design of dream scrolls which are simultaneously map, chronicle and souvenir for Western visitors to Splendid China

- Assignment 2 A new parkscape on the site for the installation of the miniatures

- Assignment 3. A programmatic proposal for Disney's new History Theme Park in Virginia.

Please research Aristotle's Kinetic school, the role of text and image space in Paul Klee's paintings, and Olmsted's construction of the Ramble in Central Park.

Required reading: Calvino's Invisible Cities, Diller and Scofidio on war and tourism, Deleuze and Guattari on practices of Nomadism.

In the meantime, two developments proceed rapidly on the edges of Splendid China. The unlikely team of Chen and Ma have parted ways; the Chen family is now developing Formosa Gardens, a 500-acre residential and entertainment complex on one side of the park. Ma and China Travel Services is developing the Asian World Trade Center on another 325 acres. Orlando is at a point of crossover from the most popular vacation spot in America to the most popular convention center in the world. If these are built, Splendid China will transform its spatial definition from destination to detour and become a grounds feature of these two business ventures, an internal attraction, an entertaining respite, a distraction for business travelers. Relieved of any pretension to commercial self-sufficiency, it could perform a mutated return, becoming a "Royal Travel Park" for business potentates of the third millennium. While I look forward to the dream journeys of my hypothetical architectural project, this may be the most fantastic solution of all.

\section{REFERENCES}

Bachelard, Gaston. "Miniature." The Poetics of Space. Boston: Beacon Press, 1969.

de Certeau, Michel. "Walking in the City." The Practice of Everyday Life. Berkeley and Los Angeles: University of California Press, 1984.

Ortiz, Valerie. "A Twelfth Century Chinese Pictorial Dream Journey." The Art Bulletin, June 1994, pp. 257 - 278. 